Dibo, M. / Journal of Yasar University, 2020, 15/57, 15-23

\title{
Vergi Yükü, Gelir, Genç Bağımlılı̆̆ı ve Tasarruflar: G-7 Ülkeleri Üzerine Bir Uygulama
}

\section{Tax Burden, Income, Young Age Dependency and Savings: An Application to G-7 Countries}

\author{
Mete DİBO, Hitit Üniversitesi, Türkiye, metedibo@ hitit.edu.tr \\ Orcid No: 0000-0002-7775-0673
}

\begin{abstract}
Öz: Büyüme ve kalkinma üzerinde yarattı̆̆ olumlu etkiler dikkate alındığında tasarruf hacminin hangi faktörler aractlığıyla değiş̧tirilebileceğine yönelik tartışmalar güncelliğini her zaman korumaktadır. Kişi ve kurumların tasarruf ve harcamalarinı belirleyen iki önemli faktörden birisi elde ettikleri gelir ve bir diğeri de katlandıkları vergi oranlarıdır. Yaşam döngüsü modeline göre genç ve emeklilerin tasarruf açı̆̆l söz konusudur. Dolayısıyla daha yüksek bağımlılık oranı tasarrufların daha düşük olmasına neden olmaktadır. Genç yaştaki nüfus bağımlılı̆̆ııın artması çalışan nüfusun tüketim harcamalarını arttırarak elde ettikleri gelirden daha azını tasarrufa ayırmalarına neden olabilmektedir. Diğer taraftan vergi yükünün artması harcanabilir gelir üzerinde yarattığı negatif etki dolayısıyla tasarruf oranlarının azalmasına yol açabilmektedir. İlgili kapsamda genç nüfusun bağımllık oranı, kişi başına gelir artışı ve vergi yükünün toplam tasarruflar üzerindeki etkisinin değerlendirilmesi bu çallşmanın amacın oluşturmaktadır. Ilgili amaç kapsamında G-7'ye dâhil olan ülkelerin 1979-2017 dönemine ait verileri kullanlarak ARDL (Autoregressive Distributed Lag Models) sinır testi gerçekleştirilmiştir. Ulaşılan sonuçlara göre vergi yükünün artması ulusal tasarrufları negatif etkilerken kişi başııa gelirdeki artış ise tasarrufları pozitif yönde etkilemektedir. Genç bağımlılık oranı göstergesine ilişkin katsayı negatif olmasına karşın olasıllı değerleri anlamlı görünmemektedir.
\end{abstract}

Anahtar Kelimeler: Vergi Yükü, Gelir, Genç Yaş Bağımlılı̆ğ, Tasarruf

JEL Siniflandirmast: C19, E21, H20, J11

Abstract: Since the saving capacity has positive effects on growth and development, the discussions about the factors that can be used to change the saving rate are always up to date. Income and taxes are two important factors determining the saving and expenditures of both individuals and institutions. According to the life cycle model, saving is negative for young who do not work and for the retired. Therefore, the higher the dependency rate, the lower the saving. The increase in the dependency of the young age population can cause the working population to increase their consumption expenditures and to allocate less of their income to saving. On the other hand, the increase in tax burden may lead to a reduction in saving rates due to its negative impact on disposable income. In this context, the aim of this study is to evaluate the effects of young age dependency rate, increase in per capita income and tax burden on gross national saving. For this purpose, ARDL (Autoregressive Distributed Lag Models) boundary test is applied by using the data of G-7 countries for the period of 1979-2017. According to the test results, the increase in tax burden negatively affects national saving, while the increase in per capita income positively affects the saving. Although the coefficient of the young age dependency ratio is negative, the probability value is not significant.

Key Words: Tax Burden, Income, Young Age Dependency, Saving JEL Classification: C19, E21, H20, J11

\section{Giriş}

Maliye politikaları ulusal tasarrufların arttrılmasında önemli bir rol oynamaktadır. Bir maliye politikası aracı olan vergilerin ulusal tasarruflar üzerinde yol açabileceği etkiler farklılaşmaktadır. Vergi yükünün artması tasarruflar üzerinde üç farklı etki ortaya çıkarabilir. Bunlardan ilkine göre devlet otoritesi vergi gelirlerini arttırarak bunları kamu tasarrufuna dönüştürebilirse toplam tasarruf düzeyinin artması mümkün olabilir. Diğer taraftan toplanan vergi gelirlerinin tüketime yönlendirilmesi durumunda ise bir yandan artan vergiler nedeniyle bireysel tasarruflar azalırken diğer yandan da kamu sektörü harcamalarının artması toplam tasarruf oranları üzerinde azaltıcı etki yaratacaktır.

Yeni Klasik yaklaşım bakış açısıyla Diamond (1965), uzun dönemde dış borçlanmadan kaynaklı faizlerin ödenebilmesi için vergilerin arttırılacağını, vergilerin ise mükelleflerin elde edilebilir yaşam boyu tüketimini doğrudan azaltıcı etki göstereceğini belirtmektedir. Bu şekilde harcanabilir gelirin azalmasına neden olan vergiler aynı zamanda tasarrufların ve dolayısıyla da sermaye stokunun azalmasına yol açmaktadır (Diamond, 1965, 1126).

Vergilerdeki değişikliklerin ulusal tasarruflar üzerinde herhangi bir farklılık yaratmaması da söz konusu olabilir. Örneğin Ricardocu Denklik Hipotezine göre vergilerdeki bir azalma ulusal tasarruflarda bir değişim meydana getirmeyecektir. Çünkü özel tasarruflardaki artı̧̧ kamu tasarruflarındaki azalmayla dengelenecektir. Bunun nedeni rasyonel bireylerin, vergilerdeki azalmanın gelecekte kendilerine bir vergi yükü olarak döneceğini biliyor olmalarıdır. Ancak özel sektörün bir bölümü likidite sorunu ile karşı karşıya ise bireyler yeterince tasarrufa yönelemeyecek ve vergilerdeki azalmaya karşın ulusal tasarruflar da azalacaktır (Hussain ve Brookins, 2001, 158).

Tasarruflar üzerinde etkisi bulunan diğer önemli değişkenler büyüme oranı ve kişi başına gelir artışıdır. Geleneksel talep teorisine göre tasarruflar, tüketicilerin gelirlerini harcayabilecekleri birçok maldan biridir. Buna göre gelir hem bireysel hem de ulusal tasarrufların temel belirleyicisi olarak görülmekte ve Keynes tarafindan da üstün mal olarak ifade Makale Gecmisi / Article History 
edilmektedir (Modigliani, 1986, 298). Keynes'e göre cari kullanılabilir gelirin artması, hanehalkı tasarruflarını arttırmaktadır. Modigliani (1966, 1970)'nin Yaşam Boyu Gelir Hipotezi'ne (YBGH) göre de ekonomik büyüme ve gelir artışı özel tasarrufları arttırmaktadır (Düzgün, 2009, 174).

Modigliani, büyümenin tasarruf üzerindeki etkisini ülkeler temelinde test etmeye yönelik ilk girişimlerin Houthakker (1965) tarafından gerçekleştirildiğini belirtmektedir. Modigliani de bu girişimleri destekleyen çalışmalar gerçekleştirmiş ve hem büyümenin hem de demografik yapının ulusal tasarrufları güçlü bir biçimde açıkladığı sonucuna ulaşmıştır. Modigliani, büyümenin ve demografik yapının yol açtığı bu etkinin yaşam döngüsü hipotezinin özünü oluşturduğunu ifade etmektedir (Deaton, 2005, 97).

Tasarruflar üzerinde etkisi olan bir başka faktör nüfusun bağımlılık oranıdır. Yaşam döngüsü hipotezinin genel sonuçlarından birisi ulusal tasarruf oranları ile nüfusun yaş yapısı arasındaki ilişkinin varlığıdır. Çalışan nüfus daha fazla tasarruf yaparken çalışmayan nüfus ise daha az tasarruf etmekte ve hatta tasarruf açığı vermektedir. Dolayısıyla çalışan nüfus oranının artması ekonomideki genel tasarruf oranını arttıracaktır (Kwack ve Lee, 2005: 865-866). Çalışmayan nüfus (bağımlı nüfus) genç veya yaşlı nüfus grubunda yer alabilir. Nüfusu yaşlanma eğiliminde olan endüstrileşmiş ülkelerde tasarruf oranlarının azalması, gelecek yıllarda kamu açıklarının artmasına neden olabilmektedir (Masson, Bayoumi ve Samiei, 1995).

Nüfus yaş yapısının ulusal tasarruflar üzerindeki etkisine ilişkin olarak gerçekleştirilen uygulamalı çalışmalar elde ettikleri sonuçlar bakımından farklılık göstermektedirler. Bu farklılıklar sonucunda tartışmaların esas olarak iki ana eksende toplulaştığını söylemek mümkündür. Bunlardan ilki, Leff (1969)'in araştırma sonuçlarına dayanmaktadır. Bu çalışmaya göre yaşlı nüfus bağımlılık oranı toplam tasarruf oranları üzerinde negatif etki yaratmaktadır. Diğer taraftan Adams (1971) ve Gupta (1971) tarafından gerçekleştirilen çalışmaların sonucuna göre ise bağımlılık oranı tasarruflar üzerinde anlamlı bir etki yaratmamakta ve hatta bu etki pozitif yönde olabilmektedir (Li, Zhang ve Zhang, 2007, 139). Li ve diğerleri (2007), bu çalışmalara katkı olarak yaşam beklentisi değişkenini de analizlerine dâhil etmişler ve bu değişkenin tasarruflar üzerinde olumlu bir etkisinin bulunduğu sonucuna ulaşmışlardır.

Ando - Modigliani (1963) - Brumberg (1956) - Houthakker (1965)'ın yaşam döngüsü hipotezine ilişkin tasarruf fonksiyonundaki temel değişkenler kişi başına gelir, gelirdeki veya milli gelirdeki artış ve nüfusun yaş yapısı (bağımlılık oran1) olarak belirtilmektedir (Ram, 1982, 538). Bu tasarruf fonksiyonu ise aşağıdaki şekilde ifade edilmektedir.

$$
S=f(D A, D B, G, P C I)
$$

Fonksiyonda S tasarruf oranını, DA ve DB bağımlılık oranlarını, G gelir artış oranını ve PCI da kişi başına geliri temsil etmektedir (Ram, 1982, 538).

$\mathrm{Bu}$ çalışmanın çıkış noktasını sözü edilen fonksiyon oluşturmakla birlikte toplam bağımlılık oranı ile yaşlı bağımlılık oranının birinci fark durağan olmaması ve ARDL modellerinde ikinci derece durağan olan değişkenlerin modele dâhil edilememesi nedeniyle analizde yalnızca genç bağımlılık oranı kullanılmıştır. Büyüme verileriyle gerçekleştirilen analizlerde karşılaşılan tanısal istatistik problemleri nedeniyle gelir göstergesi olarak kişi başına gelirdeki artış değiş̧keni kullanılmıştır. İlgili kısıtlar çerçevesinde çalışmada öncelikle konuya ilişkin uygulamalı çalışmalar aktarılmış ve daha sonra 1979-2017 dönemine ilişkin toplam ulusal tasarruf/milli gelir, toplam vergi gelirleri/milli gelir, yıllık kişi başına gelir artışı ve genç bağımlılık oranı verileri kullanılarak gecikmesi dağıtılmış otoregresif (ARDL) sınır testi gerçekleştirilmiştir. Çalışma, yaşam döngüsü yaklaşımının tasarruf fonksiyonunda yer alan temel değişkenlerden farklı olarak vergi yükü değişkenini analizlere dâhil etmesi ve bu analizlerin G-7 ülkeleri özelinde gerçekleştirilmesi yönleriyle benzer çalışmalardan ayrışmaktadır.

\section{Literatür}

Tasarrufun belirleyicilerine ilişkin gerçekleştirilen ampirik çalışmalarda toplam tasarrufun ölçüsü olarak hanehalkı tasarrufları ve toplam ulusal tasarruf göstergelerinin kullanıldı̆̆ı gözlemlenmektedir. Kullanılacak göstergenin belirleyicisinin ise verilere erişilebilirlik olduğu ifade edilebilir. Analizlerini yaşam döngüsü modeline dayandıran çalışmalar her iki tasarruf göstergesini de kullanabilmektedir. Hanehalkı tasarrufları veya ulusal tasarruf göstergeleri kullanılsın bu analizlerde nüfus artışı veya bununla ilişkili demografik göstergelerin (bağımlılık oranı gibi) toplam tasarruflar üzerindeki etkisi değerlendirilmektedir. İlgili çerçevede gerçekleştirilmiş olan uygulama sonuçlarına aşağıda yer verilmektedir.

Leff (1969), tek denklemli regresyon analizi kullanarak bağımlılık oranlarının toplam ulusal tasarruf oranlarının önemli bir belirleyicisi olduğunu öne sürmüştür. 74 ülke kapsamında ve 1964 y1lı için gerçekleştirdiği çalışmasında tüm ülkeleri birlikte ele aldığı gibi gelişmiş ve az gelişmiş ülkeler bakımından da ayrıca analizler gerçekleştirmiştir. Bulgularına göre doğum oranları azaltılmadıkça gelişmekte olan ülkelerde tasarrufların dikkate değer biçimde artması olanaklı görünmemektedir (Leff, 1969).

Ram (1982), 121 ülke kapsamında 1970-1977 dönemine ilişkin gerçekleştirmiş olduğu regresyon analizi sonucunda az gelişmiş ülkelerde, yüksek bağımlılık oranı ile toplam ulusal tasarruflar arasında ters yönlü ve anlamlı bir ilişki olduğuna dair kanıtların zayıf olduğunu ortaya koymuştur. Gelişmiş ülkeler grubunda ise yalnızca yaşlı bağımlılık oranları ile tasarruflar arasında anlamlı ve ters yönlü bir ilişki tespit etmiştir (Ram, 1982, 537-538-539).

Khan ve diğerleri (1994), Pakistan ekonomisinde özel tasarrufların belirleyicilerini araştırmak üzere gerçekleştirdikleri analiz sonucunda kişi başına milli gelir artışının tasarruflar üzerinde güçlü ve pozitif bir etkisinin bulunduğunu, borç/milli gelir oranı ile bağımlılık oranının ise ulusal tasarruflar üzerinde negatif etki yarattı̆̆ını belirtmişlerdir (Khan'dan Aktaran Ahmad, 2015, 111). 
Kim ve Zang (1997), 1960-1992 dönemini 7 alt döneme ayırarak 93 ülke kapsamında dengesiz panel analizi gerçekleştirmişlerdir. Bağımlılık oranları ile toplam tasarruflar arasındaki ilişkiyi belirlemek üzere ülkelere ve döneme özgü sabit etkiler yöntemi ile uygulanan Granger-Sims-Gweke nedensellik testine dayalı olarak gerçekleştirdikleri analiz sonucunda bağımlılık yükünün toplam tasarruf oranlarında önemli etkilere yol açtığını belirtmişlerdir (Kim ve Zang, 1997, 30-31-34). Sonuçlarına göre genç yaş bağımlılık oranı gelişmekte olan (OECD üyesi olmayan) ülkelerin tasarruf oranlarının tahmininde etkili olmaktayken yaşlı bağımlılık oranlarının ise herhangi bir etkisi bulunmamaktadır. Bunun aksine OECD ülkelerine ilişkin toplam tasarruf oranlarının tahmininde yaşlı bağımlılık oranı belirleyici olurken genç bağımlılık oranlarının etkisi tespit edilmemiştir (Kim ve Zang, 1997, 33).

Cardenas ve Escobar (1998), Kolombiya ekonomisinde tasarrufların belirleyicilerini tespit etmek için gerçekleştirdikleri korelasyon ve nedensellik analizleri sonucunda şehirleşme ve bağımlılık oranındaki artışların özel tasarrufları olumsuz etkilediğini ortaya koymuşlardır. Ayrıca yüksek vergilerin de özel tasarrufların azalmasında önemli bir fonksiyonu olduğunu belirtmişlerdir. Ulusal tasarrufların arttırılması için kamu sektörü tasarruf oranlarının arttırılmasını önermektedirler (Cárdenas ve Escobar, 1998, 5-7).

Masson ve diğerleri (1995), sanayileşmiş ve gelişmekte olan ülkeleri dikkate alarak özel tasarrufların belirleyicilerini tespit etmeye çalışmışlardır. Yatay kesit ve zaman serisi kullanarak gerçekleştirilen analizler sonucunda hükümetin mali politikalarının ulusal tasarruflar üzerinde belirleyici rolü olduğunu, sanayileşmiş ülkelerin çoğunluğunda yaşlanmanın özel tasarrufları baskıladığını, gelişmekte olan ülkelerde kişi başına gelirdeki artışın tasarrufları arttırdığını ancak belirli bir gelir düzeyinden sonra tasarrufların azaldığını belirtmişlerdir (Masson vd., 1995).

Fry ve Mason (1982) ve Mason (1981, 1987, 1988), çocuk sayısında artış olduğunda genç ailelerin tüketim gerekliliğinin arttığını ve dolayısıyla yüksek orandaki genç bağımlılığının tasarrufları baskılayabildiğini ve ekonomik büyümenin tasarruflar üzerindeki etkisini azalttığını ortaya koymuşlardır. Araştırmacılara göre bağımlılık oranları düşük ve ekonomik büyümenin hızlı olduğu bir durumda ulusal tasarruflar artmaktadır (Fry ve Mason'dan Aktaran Bloom vd., 2003, 320).

Kelley ve Schmidt (1996), 65 az gelişmiş ve 23 gelişmiş ülke ekonomisi ve 1960-1990 dönemi kapsamında gerçekleştirdikleri panel veri analizleri sonucunda tasarrufların bağımlılık oranı ve büyüme oranına duyarlı olduğunu tespit etmişlerdir (Kelley ve Schmidt, 1996, 369-378).

Athukorala ve Tsai (2003), Tayvan'da hanehalkı tasarruflarının belirleyicilerini 1952-1999 dönemi verilerini kullanarak tespit etmeye çalışmışlardır. Tasarrufun belirleyicisi olarak enflasyon, harcanabilir gelir artış oranı, işsizlik oranı, genç bağımlılık oranı, kamu tasarrufları, firma tasarrufları, reel faiz oranı, hanehalkı malvarlığı ve sosyal güvenlik ödemeleri kullanılmıştır. Hayat döngüsü hipotezinden yararlanılarak oluşturulan tasarruf fonksiyonundan hareketle ARDL sınır testi yaklaşımı kullanılmış ve analizler neticesinde harcanabilir gelirdeki artış ile reel faiz oranının hanehalkı tasarruflarını pozitif yönde etkilediğini ortaya koymuşlardır. Genç bağımlılığı, kamu tasarrufları, sosyal güvenlik ödemeleri ve kredi olanaklarına erişimin hanehalkı tasarrufları üzerinde negatif etki yarattığını tespit etmişlerdir. İşsizlik oranındaki kısa vadeli değişiklikler ise ihtiyati amaçlı tasarrufları pozitif yönde etkilemektedir (Athukorala ve Tsai, 2003).

Kwack ve Lee (2005), ulusal tasarruf oranlarının kişi başı milli gelir artış oranından, konut stokunun milli gelire oranından, yaşlı ve genç bağımlılık oranından ve yabancı tasarruflardan etkilendiği sonucuna ulaşmışlardır. Kore ekonomisi için 1975-2002 dönemine ait verilerle uygulanan analiz sonuçlarına göre genç ve yaşlı bağımlılık oranlarındaki $\% 1$ 'lik artış toplam tasarruf oranını sırasıyla \%0.15 ve \%0.34 oranında azaltmaktadır (Kwack ve Lee, 2005, 871).

Li ve diğerleri (2007), 1960-2004 dönemini ve 200 ülkeyi kapsayan çalışmalarında yaşam beklentisi, nüfus artış1 ve yaşlı bağımlılık oranının tasarruf, yatırım ve kişi başına üretim artışı üzerindeki etkilerini panel veri analiziyle araştırmışlardır. Araştırma sonuçlarına göre yaşam süresinin uzaması tasarruf oranları üzerinde pozitif etkiye yol açmaktayken bağımlılık oranının artması ise tasarrufları negatif etkilemektedir. Diğer taraftan kişi başına gelir düzeyi arttıkça bu gelirin tasarruftan daha çok tüketime ayrıldığı sonucuna varmışlardır. Yaşam beklentisi ile nüfusun yaş yapısının büyüme üzerinde önemli katkıları olduğu bulgusuna da ulaşmışlardır (Li, Zhang ve Zhang, 2007, 138-143-144151).

Xu (2012), Çin’de nüfus yaş yapısı ve ekonomik büyümenin tasarruf oranı üzerindeki etkisini araştırmıştır. 1963 2006 dönemine ait verileri kullanarak gerçekleştirdiği Vektör Hata Düzeltme Modeli (VECM) ve Engle Gramger Koentegrasyon testlerine göre genç ve yaşlı bağımlılık oranları hanehalkı tasarruflarını negatif etkilerken kişi başına milli gelir ise hanehalkı tasarruf oranlarını pozitif etkilemektedir (Xu, 2012).

Arıç (2015), 21 APEC (Asya-Pasifik Ekonomik İşbirliği) ülkesini dâhil ettiği ve 2000-2013 dönemini ele aldığı panel veri analizi sonucunda gelir, bağımlılık oranı, genç nüfus, kırsal nüfus ve kent nüfusu değişkenlerinin tasarrufları pozitif etkilediğini gözlemlemiştir. Finansal derinlik ise tasarrufları negatif etkilemektedir. Enflasyon ve yaşlı nüfus değişkenlerinin ise tasarruflar üzerinde anlamlı bir etkisi bulunmamıştır (Arıç, 2015, 113).

Ahmad (2015), Pakistan'ın 1972-2012 dönemini kapsayan zaman serisi verilerini dâhil etmiş, uzun dönem nedensellik ilişkisini analiz etmek üzere Toda Yomamoto tekniğini ve kısa dönem nedenselliği test etmek için de Granger nedensellik testini kullanmıştır. Sonuçlarına göre kişi başına gelir, enflasyon oranı ve bağımlılık oranına ilişkin göstergeler özel tasarruf oranları üzerinde anlamlı etkiler yaratmaktadır (Ahmad, 2015, 103) .

Kapingura ve diğerleri (2015), Güney Afrika Kalkınma Topluluğu üzerine 1980-2009 dönemi kapsamında panel eşbütünleşme ve dinamik en küçük kareler yöntemlerini kullanarak gerçekleştirdikleri analizler sonucunda gelir, finans sektörün gelişmişliği ve yabancı sermayenin tasarruflar üzerinde pozitif etkisi olduğunu tespit etmişlerdir. Diğer taraftan faiz oranları ile bağımlılık oranları tasarruflar üzerinde negatif etki yaratmaktadır (Kapingura, Ikhide, ve Tsegaye, 2015, 2107). 
Doker ve diğerleri (2016), 1993-2013 dönemine ilişkin bağımlılık oranı, kişi başına gelir artışı, nüfus yoğunluğu, şehir nüfusunun toplam nüfus içindeki oranı, kadın işgücüne katılım oranı ve işsizlik oranını kullanarak panel veri analizi gerçekleştirmiş̧lerdir. 20 geçiş ekonomisini dahil ettikleri analiz sonucunda kişi başına gelir artış oranı ve bağımlılık oranının her ikisinin de ulusal tasarrufları pozitif yönde etkilediğini bulgulamışlardır (Doker, Turkmen, ve Emsen, 2016, 275-281).

Kaya ve diğerleri (2017), 1980-2015 dönemi için Türkiye’de yaşam beklentisindeki artışın tasarruflar üzerindeki etkisini ARDL yöntemi ile test etmişlerdir. Toplam tasarruf, kişi başına gayri safi yurtiçi hasıla, bağımlı nüfus oranı, doğumda yaşam beklentisi, 65 yaş üzeri yaşam beklentisi ve mevduat faiz oranı değişkenlerini kullanarak gerçekleştirdikleri analiz sonucunda doğumda yaşam beklentisi ve bağımlı nüfus oranındaki artışın toplam tasarruflar üzerinde negatif etki yarattığını bulgulamışlardır. Kişi başına gelir ise toplam tasarrufları uzun dönemde negatif etkilemektedir (Kaya, Kete, ve Aydın, 2017, 368-373-377).

\section{Veri Seti, Yöntem ve Bulgular}

Bu çalışmada G-7'ye dâhil olan ülkelerin (Almanya, Amerika Birleşik Devletleri, Fransa, İngiltere, İtalya, Japonya, Kanada) 1979-2017 dönemine ait toplam ulusal tasarruf/milli gelir, toplam vergi gelirleri/milli gelir, yıllık kişi başına gelir artışı ve genç bağımlılık oranı (15 yaş altı nüfusun çalışan nüfusa oranı) değişkenleri kullanılarak ARDL (Autoregressive Distributed Lag) sınır testi gerçekleştirilmiştir. Analizde kullanılan vergi yükü (toplam vergi gelirlerinin milli gelire oranı) değişkenine ait veriler Ekonomik İşbirliği ve Kalkınma Teşkilatı (Organisation for Economic Cooperation and Development- OECD) istatistiklerinden, diğer değişkenlere ilişkin veriler ise Dünya Bankası (World Bank) istatistiklerinden elde edilmiştir. Analizlerin gerçekleştirilmesinde EViews 10 ekonometri paket programından yararlanılmıştır. Analizde değişkenlerin kısaltmaları kullanılmış ve bu kısaltmalara yönelik açıklama Tablo 1'de belirtilmiştir.

Tablo 1. Analizde Kullanılan Kısaltmalar ve Açıklamaları

\begin{tabular}{|l|l|}
\hline Değişken & \multicolumn{1}{c|}{ Açıklama } \\
\hline TAS & Toplam ulusal tasarrufların milli gelire oranı \\
\hline VRGYK & Vergi gelirlerinin milli gelire oranı \\
\hline$K B G$ & Kişi başına milli gelir artış oranı \\
\hline GNCB & Genç yaş bă̆ı̆mlılık oranı \\
\hline
\end{tabular}

ARDL sınır testi, değişkenlerin düzeyde - I(0) veya birinci düzeyde $\mathrm{I}(1)$ - durağan oldukları varsayımına dayanmaktadır. Dolayısıyla sınır testinin gerçekleştirilmesinden önce tüm değişkenlerin bütünleşme derecelerinin belirlenmesi gerekmektedir. Buradaki amaç, değişkenlerin ikinci düzey - I(2) durağan olmadıklarının tespit edilmesi ve böylece sahte sonuçlarla karşılaşılmasının önlenmesidir. İkinci derece bütünleşik olan değişkenlerin varlığ halinde F istatistik değerleri yorumlanamamaktadır (Belloumi, 2014, 277). Tablo 2'deki birim kök testi verilerine göre bu çalışmada kullanılan seriler farklı dereceden [I(0), I(1)] durağandır ve ARDL modelinin kullanımı uygundur.

Tablo 2. Birim Kök (ADF) Testi Sonuçları

\begin{tabular}{|c|c|c|}
\hline & \multicolumn{2}{|r|}{ G-7 } \\
\hline Değişken & t-istatistiği (sabitte) & t-istatistiği (sabitte ve trendde) \\
\hline$T A S$ & $I(1)-4.1914 *$ & $I(1)-4.1286^{*}$ \\
\hline$V R G Y K$ & $I(1)-5.2925 *$ & $I(1)-5.1370^{*}$ \\
\hline$K B G$ & $I(0)-4.4671 *$ & $I(0)-4.7108^{*}$ \\
\hline$G N C B$ & $I(1)-4.8405^{*}$ & $I(1)-4.4211 *$ \\
\hline
\end{tabular}

Birim kök testinden sonra ARDL modellerinde yapılması gereken gecikme uzunluklarının belirlenmesidir. Gecikme uzunlukları en çok 5 gecikme uzunluğuna ve Akaike bilgi kriterine göre her bir değişken için otomatik seçim yöntemiyle belirlenmiştir. Buna göre gecikme uzunlukları TAS (5), VRGYK (3), KBG (1) ve GNCB (2) olarak tespit edilmiştir. Bu aşamadan sonra ARDL modeli aşağıdaki şekilde tahmin edilmiş ve modele ilişkin tanısal istatistikler Tablo 3 'te aktarılmıştır.

$$
\Delta T A S_{t}=\alpha_{0}+\sum_{i=1}^{j} \alpha_{1} \Delta T A S_{t-1}+\alpha_{2} V R G Y K_{t-1}+\alpha_{3} K B G_{t-1}+\alpha_{4} G N C B_{t-1}+\mu_{t}
$$

Tablo 3. ARDL Modeli $(5,3,1,2)$ Tanisal İstatistikleri

\begin{tabular}{|l|c|}
\hline Breusch-Godfrey LM & $0.6829(0.6440)$ \\
\hline Breusch-Pagan-Godfrey & $0.5919(0.8395)$ \\
\hline Jarque-Bera & $1.5185(0.4680)$ \\
\hline
\end{tabular}

Parantez içerisinde olasılık değerleri yer almaktadır. 
Tablo 3 'ten elde edilen bulgular neticesinde, kurulan modelde otokorelasyon (Breusch-Godfrey LM Testi) ve değişen varyans (Breusch-Pagan-Godfrey Testi) sorununun bulunmadığı, hata teriminin de normal dağılıma (Jarque-Bera Testi) uyduğu anlaşılmaktadır. Dolayısıyla değişkenler arasında kısa ve uzun dönem ilişkiyi ortaya koymak üzere ARDL modelinin kurulmasında bir engel bulunmamaktadır.

Kısa ve uzun dönem ilişkinin tespit edilmesinden önce seriler arasında eşbütünleşmenin var olup olmadığını araştırmak üzere sınır testi gerçekleştirilmektedir. Sınır testiyle değişkenler arasında eşbütünleşmenin var olup olmadığ1 tespit edilmektedir. Test sonuçlarına göre test istatistiği üst kritik sınırı aştığında kısa ve uzun dönem katsayıları tahmin edilebilmektedir.

Tablo 4. ARDL Sinır Testi

\begin{tabular}{|l|c|}
\hline F-istatistiği & 21.13 \\
\hline Alt Sinır I(0) & $3.65^{*}$ \\
\hline Üst Sinır I(1) & $4.66^{*}$ \\
\hline
\end{tabular}

Gerçekleştirilen sınır testi sonuçlarına göre F istatistiği değeri alt ve üst sınırlardan yüksektir. Bu değer, kritik değer olan I(1) üst sınırından daha yüksek olduğu için seride eş bütünleşme olduğuna ilişkin kurulan alternatif hipotez (H1) kabul edilmiştir. Buna göre G7 ülkelerine ilişkin seriler arasında \%1 anlamlılık seviyesinde eşbütünleşme bulunmaktadır.

Sınır testi ile değişkenler arasında uzun dönemli bir ilişki tespit edilmiş olduğundan, bir sonraki aşamada uzun dönem katsayılarının tahminine geçilmektedir (Akel ve Gazel, 2014, 31).

Uzun dönem katsayıların tahmininde kullanılan model aşağıda ifade edildiği gibidir.

$$
T A S_{t}=\alpha_{0}+\sum_{i=1}^{k} \alpha_{1 i} T A S_{t-i}+\sum_{i=0}^{m} \alpha_{2 i} K B G_{t-i}+\sum_{i=0}^{m} \alpha_{3 i} V R G Y K_{t-i}+\sum_{i=0}^{m} \alpha_{4 i} G N C B_{t-i}+\mu_{t}
$$

Tablo 5. Uzun Dönem Sonuçları ARDL $(5,3,1,2)$

\begin{tabular}{|c|c|c|}
\hline Açıklanan Değişken: TAS & & \\
\hline Değişkenler & Katsayı & t-istatistiğ $i$ \\
\hline$K B G$ & 1.7679 & $3.6981 *$ \\
\hline$V R G Y K$ & -0.8964 & $-0.2558 * *$ \\
\hline$G N C B$ & -0.0355 & -0.2753 \\
\hline$C$ & 48.6992 & $3.1312 *$ \\
\hline
\end{tabular}

*\%1'de anlamlı, **\%5'te anlamlı.

Tablo 5' te yer alan uzun dönem sonuçlara göre kişi başına gelir artışı ve vergi yükü ile tasarruflar arasında anlamlı bir ilişki bulunmaktadır. Bu sonuçlara göre kişi başına gelir arttıkça tasarruflar artmakta ve vergi yükü arttıkça tasarruflar azalmaktadır. Genç yaş bağımlılık oranına ait katsayının negatif ve teorik açıdan beklendiği şekilde olmaşına karşın bu değişken ile tasarruflar arasında istatistiki olarak anlamlı bir ilişki söz konusu değildir. Bu sonuca benzer biçimde Adams (1971) ve Gupta (1971) tarafından gerçekleştirilen çalışmalar da bağımlılık oranı ile tasarruflar arasında anlamlı bir etki tespit edememiştir.

Vergi yükü ve tasarruflar arasındaki ters yönlü ilişkiyle alakalı olarak Akalın (2002), vergi yükü ile tasarruf hacmi arasında bir makas bulunduğunu ve bu iki göstergenin birbirlerine rakip makro büyüklükler olduğunu ifade etmektedir. Vergi yükünde ortaya çıkan artış tasarruf hacminin yanında büyüme hızı ile gelecekteki potansiyel vergi hasılatının da azalmasına sebep olmaktadır (Akalın, 2002, 220-221).

Uzun dönem katsayıların bu şekilde tahmin edilmesinden sonra hata düzeltme modeli tahmin edilmiştir. Hata düzeltme modelinin temel amacı uzun dönem dengede meydana gelen sapmaların ne kadar hızla düzeldiğini ortaya koymaktır (Ahmed ve Delin, 2019, 94). Kısa dönem sonuçlarının yer aldığ1 Tablo 6’ya göre hata düzeltme katsayısının işareti negatif ve anlamlıdır. Hata düzeltme katsayısının [EC(-1)] negatif ve istatistiksel olarak anlamlı olması, kısa dönemde meydana gelen dengeden sapmaların uzun dönemde dengeye yaklaştığını işaret etmektedir (Akel ve Gazel, 2014, 37).

Tablo 6. Hata Düzeltme Modeli Sonuçları ARDL $(5,3,1,2)$

\begin{tabular}{|c|c|c|}
\hline \multicolumn{3}{|c|}{ Açıklanan Değişken: TAS } \\
\hline Değişkenler & Katsayl & t-istatistiği \\
\hline$D(T A S(-1))$ & -0.0343 & -0.3674 \\
\hline$D(T A S(-2))$ & -0.0452 & -0.6083 \\
\hline$D(T A S(-3))$ & 0.2066 & $2.9919 *$ \\
\hline$D(T A S(-4))$ & -0.1671 & $-2.7151 * *$ \\
\hline$D(K B G)$ & 0.1942 & $1.6872 *$ \\
\hline$D(V R G Y K)$ & -0.2686 & $-2.3182 * *$ \\
\hline
\end{tabular}


Dibo, M. / Journal of Yasar University, 2020, 15/57, 15-23

\begin{tabular}{|l|c|c|}
\hline$D(V R G Y K(-1))$ & 0.2685 & $2.9595 *$ \\
\hline$D(V R G Y K(-2))$ & 0.2130 & 8.1629 \\
\hline$D(G N C B)$ & -2.4024 & $-3.5874 *$ \\
\hline$D(G N C B(-1))$ & 4.1258 & $6.5220 *$ \\
\hline$E C(-1)$ & -0.2676 & $-11.310^{*}$ \\
\hline
\end{tabular}

Tahmin edilen ARDL $(5,3,1,2)$ modelinin kararlılı̆̆ının, diğer bir ifadeyle yapısal değişimin söz konusu olup olmadığını araştırmak üzere CUSUM ve CUSUM-of-Squares testleri gerçekleştirilmiş ve sonuçlara ilişkin grafik Şekil 1'de aktarılmıştır.
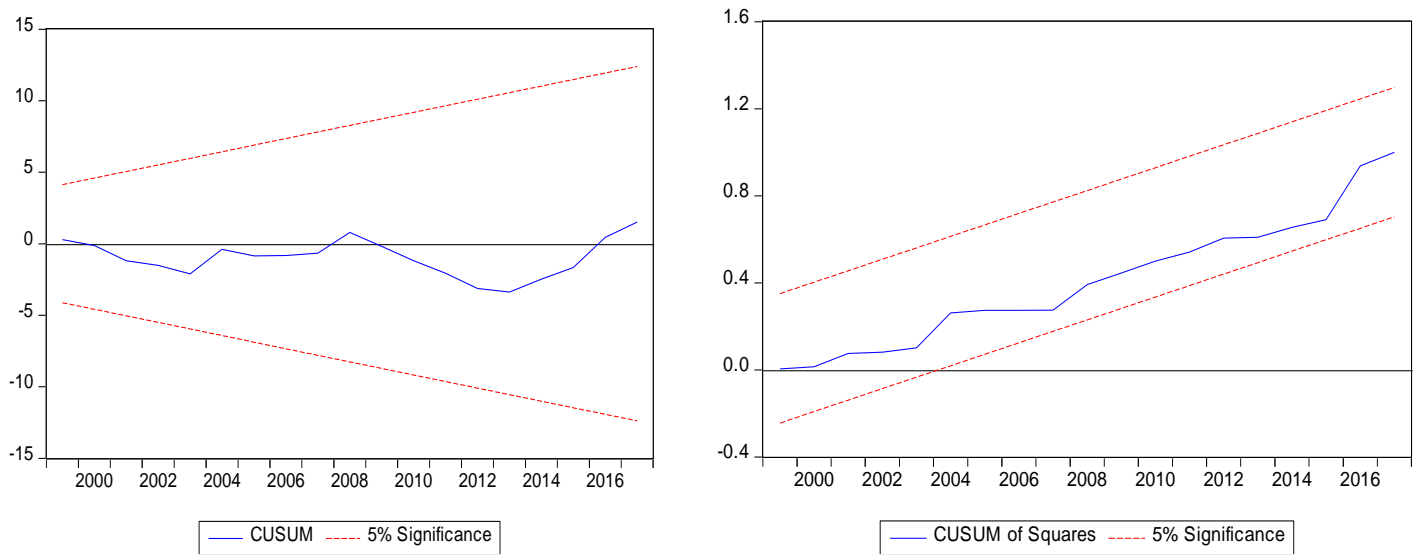

Şekil 1. CUSUM ve CUSUM Squares Testleri

CUSUM ve CUSUM of Squares istatistiklerinin \%5 anlamlılık düzeyinde kritik sınırlar içerisinde yer alması ARDL modelindeki katsayıların istikrarlı olduğunu ve kırılmayı ifade etmek üzere herhangi bir kukla değişken kullanılmadan modelin tahmin edilebileceğini göstermektedir (Demirgil, 2018: 1127; Akel ve Gazel, 2014: 36). Buna göre modelin tahmin döneminde herhangi bir yapısal kırılma bulunmamaktadır ve model güvenilirdir (Esen, Yıldırım ve Kostakoğlu, 2012, 262; Ecevit, Yücel ve Yücel 2016, 1133).

\section{Sonuç}

Modigliani ve öğrencisi Brumberg'in öncülüğünde 1950’lerde yaşam döngüsü yaklaşımına göre bireyler emeklilik dönemlerinde tüketim düzeylerini koruyabilmek amacıyla, gelir elde ettikleri dönemlerde tasarrufta bulunmaktadırlar. Dolayısıyla bir toplumda çalışma çağında olanların payı arttıkça ve gelir yükseldikçe tasarrufların artması beklenmektedir. Bunun aksine çalışma çağında olmayan nüfusun çalışan nüfus içindeki payının (genç yaş bağımlılık oranının) artması ise tasarrufların azalmasına neden olabilmektedir.

Tasarrufların belirleyicilerini tespit etmek üzere yaşam döngüsü modelinden hareketle gerçekleştirilen çalışmalarda birçok farklı değişken kullanılmasına karşın vergiyle ilişkili göstergelerin analizlere çok fazla dâhil edilmediği ve çoğunlukla mikro ölçekli verilerin kullanıldığı gözlemlenmektedir. Bu noktadan hareketle çalışmada tasarrufların göstergesi olarak toplam ulusal tasarruflar dikkate alınmış, yaşam döngüsü hipotezinde temel alınan gelir ve bağımlılık göstergelerine ek olarak vergi yükü göstergesi de analize dahil edilmiştir. G-7 ülkeleri kapsamında 1979-2017 dönemine ait vergi yükü, kişi başı milli gelir artışı ve genç yaş bağımlılık oranı göstergelerinin kullanıldığı ARDL sınır testi sonucunda ulusal tasarrufların kişi başı milli gelir artışından pozitif, vergi yükünün artmasından ise negatif etkilendiği tespit edilmiştir. Genç yaş bağımlılık oranının tasarruflar üzerindeki negatif etkisi ise istatistiki olarak anlamlı değildir. Gelişmiş ülkelerde yaşlı bağımlılık oranının daha anlamlı sonuçlar üretmesi mümkün olabilir. Ancak analizlere dâhil edilmesi planlanan yaşlı bağımlılık oranı göstergelerinin ARDL sınır testi için uygun olmaması bu çalışmanın önemli bir sınırlayıcısı olmuştur. Konuya ilişkin olarak Ram (1982) ile Kim ve Zang (1997), yaşlı bağımlılık oranları ile tasarruflar arasındaki anlamlı ve ters yönlü ilişkinin gelişmiş ülkeler grubunda geçerli olduğunu tespit etmişlerdir.

Tüketim ve tasarrufların, gelirin bir fonksiyonu olduğu düşünüldüğünde kişi başına gelir artışının tasarruflar üzerindeki pozitif etkisi tutarlı görünmektedir. Öte yandan vergi artışlarının kişi ve kurumların tüketim, tasarruf ve yatırım kararları üzerinde yarattığı caydırıcı etki göz önünde bulundurulduğunda vergi yükündeki artışın tasarruflara negatif yansıması da teorik ve uygulamalı sonuçlarla tutarlılık göstermektedir.

$\mathrm{Bu}$ çalışma çerçevesinde ulaşılan sonuçlardan hareketle kamu otoritesinin, özellikle ekonomiye aktarılmayan tasarrufları teşvik etmek ve vergi yükünü azaltmak üzere vergi muafiyet, istisna ve indirimleri ile devlet katkısı gibi araçlarla müdahalesinin etkili sonuçlar doğurabileceği belirtilmelidir. Kişi başına gelirin tasarruflar üzerindeki pozitif 
Dibo, M. / Journal of Yasar University, 2020, 15/57, 15-23

etkisini arttırılabilmek üzere beşeri sermaye, teknoloji ve altyapı yatırımları uyarılmalıdır. Bu kapsamda doğrudan kamu girişimleri söz konusu olabileceği gibi kamu teşvikli özel kesim faaliyetleri de etkili olabilecektir. 


\section{KAYNAKÇA}

Adams, N. A. 1971. Dependency Rates and Savings Rates: Comment". The American Economic Review, 61(3), 472475.

Ahmad, F. 2015. "Determinants of Savings Behavior in Pakistan: Long Run - Short Run Association and Causality". Timisoara Journal of Economics and Business, 8(1), 103-136.

Ahmed, Y. N. ve Delin, H. 2019. "Current Situation of Egyptian Cotton: Econometrics Study Using ARDL Model". Journal of Agricultural Science, 11(10), 88-97.

Akalın, G. 2002. Türkiye'de Ekonomi-Politik Kriz ve Piyasa Ekonomisine Geçiş (1. Baskı). Ankara: Akçağ Yayınları.

Akel, V., ve Gazel, S. 2014. "Döviz Kurları ile BIST Sanayi Endeksi Arasındaki Eşbütünleşme İlişkisi: Bir ARDL Sınır Testi Yaklaşımı". Erciyes Üniversitesi İktisadi ve İdari Bilimler Fakültesi Dergisi, (44), 23-41.

Ando, A., ve Modigliani, F. 1963. "The "Life Cycle" Hypothesis of Saving: Aggregate Implications and Tests". The American Economic Review, 53(1), 55-84.

Arıç, K. H. 2015. "Determinants of Savings in the APEC Countries. Theoretical and Applied Economics". 22(2), 113122.

Athukorala, P., ve Tsai, P.-L. (2003). "Determinants of Household Saving in Taiwan: Growth, Demography and Public Policy". The Journal of Development Studies, 39(5), 65-88.

Belloumi, M. 2014. The Relationship Between Trade, FDI and Economic Growth in Tunisia: An Application of the Autoregressive Distributed Lag Model. Economic Systems, 38(2), 269-287.

Bloom, D. E., "Canning, D. ve Graham, B. 2003. Longevity and Life-Cycle Savings". The Scandinavian Journal of Economics, 105(3), 319-338.

Brumberg, R. E. . 1956. "An Approximation to the Aggregate Saving Function". The Economic Journal, 66(261), 6672.

Cárdenas, M., ve Escobar, A. 1998. "Saving Determinants in Colombia: 1925-1994". Journal of Development Economics, 57(1), 5-44.

Cheema, A. R., Rehman, A., ve Adeem, M. A. 2018. "Assessing the Determinants of Savings in Pakistan: An Evidence from PSLM". European Online Journal of Social Sciences, 7(2), 366-385.

Deaton, A. 2005. "Franco Modigliani and the Life-Cycle Theory of Consumption". BNL Quarterly Review, 58(233234), 91-107.

Demirgil, B. 2018. "Vergilerin Gelir Dağılımı Üzerindeki Etkisi: Ampirik Bir Çalışma". Cumhuriyet Üniversitesi Íktisadi ve İdari Bilimler Dergisi, 19(2), 118-131.

Diamond, P. A. 1965. "National Debt in a Neoclassical Growth Model". The American Economic Review, 55(5), 11261150 .

Doker, A. C., Turkmen, A., ve Emsen, O. S. 2016. "What are the Demographic Determinants of Savings? An Analysis on Transition Economies (1993-2013)". Procedia Economics and Finance, 39(2016), 275-283.

Düzgün, R. 2009. "Türkiye'de Özel Tasarrufun Belirleyicileri". Erciyes Üniversitesi İktisadi ve İdari Bilimler Fakültesi Dergisi, (32), 173-189.

Ecevit, E., Yücel, A. G. ve Yücel, Ö. 2016. "Are Some Taxes Better than Others for Economic Growth? An ARDL Approach for Turkey". The Empirical Economics Letters, 15(11), 1129-1136.

Esen, E., Yıldırım, S., ve Kostakoğlu, S. F. (2012). "Feldstein-Horioka Hipotezinin Türkiye Ekonomisi İçin Sınanması: ARDL Modeli Uygulaması". Eskişehir Osmangazi Üniversitesi IIIBF Dergisi, 7(1), 251-267.

Gupta, K. L. 1971. "Dependency Rates and Savings Rates: Comment". The American Economic Review, 61(3), 469471.

Houthakker, H. S. 1965. On Some Determinants of Saving in Developed and Under-Developed Countries. In E. A. G. Robinson (Ed.), Problems in Economic Development (1st ed., pp. 212-227). New York: Stockton Press.

Hussain, M., ve Brookins, O. T. 2001. "On the Determinants of National Saving: An Extreme-Bounds Analysis". Weltwirtschaftliches Archiv, 137(1), 150-174.

Kapingura, F. M., Ikhide, S., ve Tsegaye, A. 2015. "Determinants of Savings in the SADC Region: The Role of Foreign Capital". The Journal of Applied Business Research, 31(6), 2107-2122.

Kaya, H., Kete, H., ve Aydın, M. S. 2017. "Türkiye’de Yaşam Beklentisi Tasarruf İlişkisi: ARDL Sınır Testi Yaklaşımı". Akademik Bakış Dergisi, (62), 368-380.

Kelley, A. C., ve Schmidt, R. M. 1996. "Saving, Dependency and Development". Journal of Population Economics, 9(4), 365-386.

Kim, Y. C., ve Zang, H. 1997. "Dependency Burden and Savings: A New Approach to the Old Query". The Journal of Developing Areas, 32(1), 29-36.

Kwack, S. Y., ve Lee, Y. S. 2005. "What Determines Saving Rates in Korea? The Role of Demography". Journal of Asian Economics, 16(5), 861-873.

Leff, N. H. 1969. "Dependency Rates and Savings Rates". The American Economic Review, 59(5), 886-896.

Li, H., Zhang, J., ve Zhang, J. 2007. Effects of Longevity and Dependency Rates on Saving and Growth: Evidence from a Panel of Cross Countries. Journal of Development Economics, 84, 138-154.

Mason, A. 1988. Saving, Economic Growth, and Demographic Change. Population and Development Review, 14(1), 113-144.

Masson, P. R., Bayoumi, T., ve Samiei, H. 1995. Saving Behavior in Industrial and Developing Countries. In Staff 
Dibo, M. / Journal of Yasar University, 2020, 15/57, 15-23

Studies for the World Economic Outlook (pp. 1-27). Washington, D.C.: International Monetary Fund. https://books.google.com.tr/books?hl=trvelr=veid=0UqGQ0HuPgACveoi=fndvepg=PT10vedq=saving+Behavio $\mathrm{r}+\mathrm{in}+$ Industrial+and+Developing+Countrie+masson+1995veots=9vvRBa2JbMvesig=YXSZ7ZtcltBeuD_mjsM mdMiGo2Yveredir_esc=y\#v=onepageveqvef=false (Erişim: 28.09.2019).

Modigliani, F. 1966. "The Life Cycle Hypothesis of Saving, the Demand for Wealth and the Supply". Social Research, 33(2), 160-217.

Modigliani, F. 1986. "Life Cycle, Individual Thrift, and the Wealth of Nations". American Economic Association, 76(3), 297-313.

Ram, R. 1982. "Dependency Rates and Aggregate Savings: A New International Cross-Section Study". American Economic Association, 72(3), 537-544.

Xu, Y. 2012. Demographic Changes, Household Savings and Economic Growth in All China: A Time-Series Approach (Master Thesis). Lund University, Lund. 